\title{
Teachers' group brings genomics revolution to minority colleges
}

When the human genome sequence was released in 1999, it meant two things to Edison Fowlks, a biology professor at Hampton University in Virginia.

First, genomics technologies were about to revolutionize science. And second, students and faculty of so-called minority-serving institutions such as Hampton, a historically black college, needed to be part of the revolution.

But where were such institutions going to come up with the funds to train faculty in the new technologies - much less buy microarrays and the scanners needed to read them?

In 2004, Fowlks found an answer when he met fellow biologist A. Malcolm Campbell, who since 2000 had been organizing a program called Genome Consortium for Active Teaching (GCAT) for faculty at small undergraduate institutions. Campbell is himself a researcher at Davidson College in North Carolina, a liberal arts college with 1,700 students.

Campbell had convinced genomics pioneer Pat Brown of Stanford University to donate microarrays, which Campbell then mailed to dozens of other professors. These professors taught students how to do experiments with the chips and then mailed them back to him. Campbell then read data from the chips using a single scanner and sent it back to the professors, who analyzed it with free software written by one of Campbell's colleagues. The only charges for chip users were shipping fees and the cost of the reagents for their experiments-no more than $\$ 500$.

Fowlks saw the power of the model immediately. "GCAT essentially democratizes genomics," he says. "It allows a consortium of small colleges and universities to do informatics

and genomics without all the powerful equipment that major universities have."

Fowlks joined forces with Campbell to expand GCAT's reach. The pair wrote a grant, awarded by the US National Science Foundation, to support a GCAT workshop at Morehouse College in Atlanta in 2005. The agency has committed to funding yearly workshops through 2009; the most recent of these, held this July,

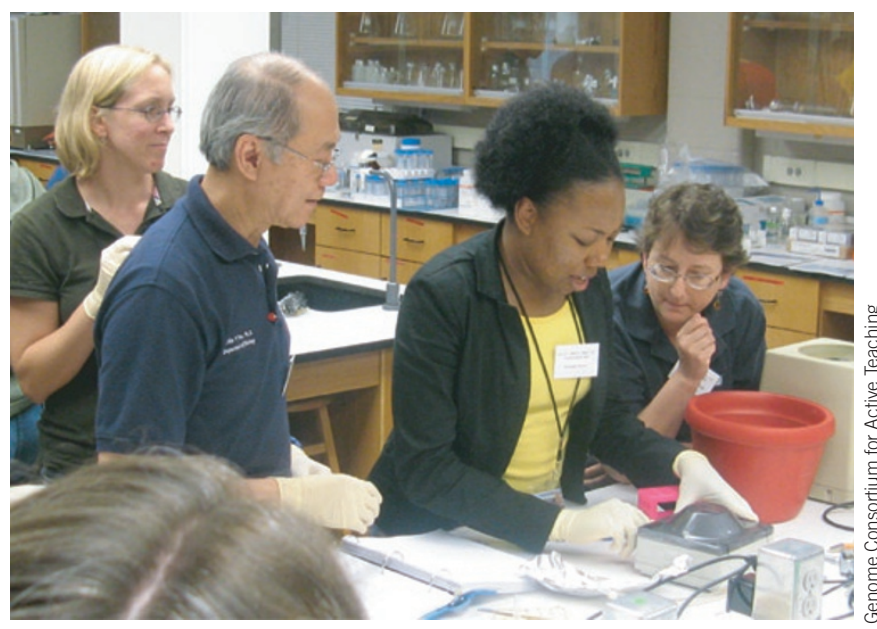

Bring on the revolution: Using donated microarrays and a single scanner, minority faculty and students are jumping into genomics research. trained 40 teachers.

The workshops are open to anyone who teaches undergraduates, with an emphasis on faculty teaching minority students. Since 2003, the Howard Hughes Medical Institute has spent $\$ 100,000$ each year to buy microchips for the program. This year, GCAT distributed 1,200 chips to 72 teachers at institutions across the nation, from Alaska to Hawaii and Puerto Rico.

This fulfills not only Fowlks's and Campbell's goals, but also those set out by numerous reports on American competitiveness, such as a 2005 National Academies manifesto that calls for the nation to train more minority scientists and engineers.

"The National Academies and so many other groups have said we need to increase diversity in science, and I don't know how that's supposed to happen if we don't reach out to schools that serve large numbers of minorities," Campbell says.

GCAT is already showing results. Scientists such as Consuelo Alvarez at Longwood University in Farmville, Virginia, are publishing genomics research, and students such as Hampton University senior Sabriya Rosemond are getting swept into the genomics revolution.

Rosemond, one of Fowlks's former students, has worked in biology labs for the past two summers and is determined to go into science after she graduates next year. "I want to make science a little browner, like Dr. Campbell and Dr. Fowlks are doing," she says. For the GCAT leaders, that's an even more satisfying benchmark than the growing list of grants and papers that they are helping to produce every year.

Erika Check, San Francisco

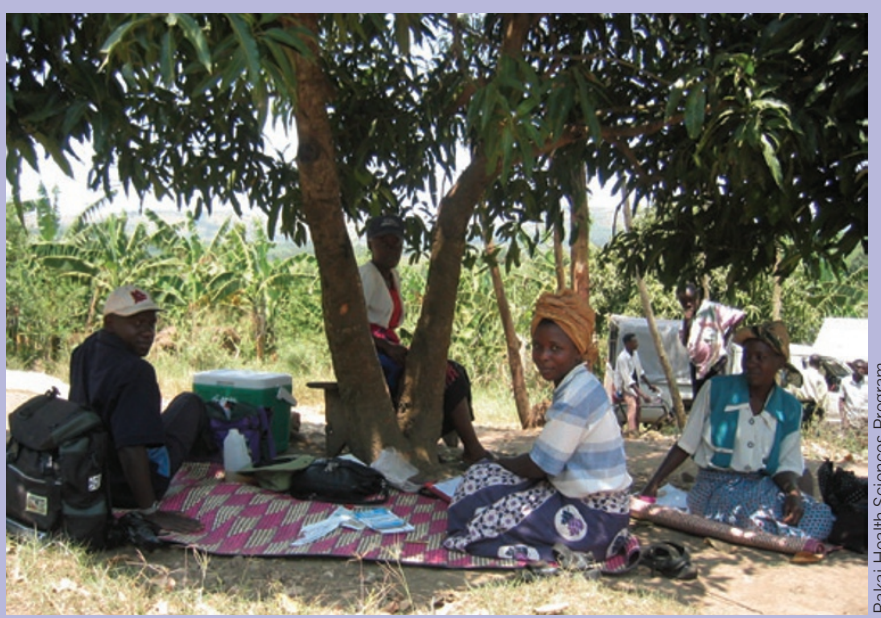

Simple solution: Women and children made swabs needed to test vaginal $\mathrm{pH}$ for a clinical study in Uganda.
The kids received their wages in gourmet gummy bears and M\&Ms. On a good night, the team would make 200 swabs.

The researchers used the swabs to follow weekly changes in vaginal $\mathrm{pH}$ in 311 women over two years. "It's a poor woman's way of doing it," says John Thorp, a gynecologist at the University of North Carolina, who was not involved in the project. "I think that taking the [vaginal] speculum out of it greatly diminishes the cost."

Sullivan and her colleagues used to joke about patenting the swab. But it's too late. In July, New York-based company Vagisil launched its own over-the-counter version, a spatula-shaped 'wand' that measures $\mathrm{pH}$.

The study ended in 2003, and the handmade $\mathrm{pH}$ swabs are no longer being used. But the researchers plan to revive their approach if necessary: a tube of $\mathrm{pH}$ strips and a box of tongue depressors are still cheaper than the $\$ 15$ tab for a Vagisil kit.

Cassandra Willyard, New York 